\title{
A política de apoio à agricultura familiar na conservação da biodiversidade no Brasil
}

\section{The Public Policy of Support to the Family Farming in Biodiversity Conservation in Brazil}

\author{
Rogério Marcos MAGALHÃES*
}

\begin{abstract}
RESUMO
Este trabalho trata inicialmente da noção de multifuncionalidade da agricultura e discorre sobre o embate internacional em torno do assunto, que coloca em posição antagônica dois grupos de países. Em seguida, enumera as funções desempenhadas pela agricultura familiar defendendo a ideia de que o Brasil atende à função ambiental da agricultura alocando recursos financeiros subsidiados aos agricultores familiares em duas linhas de crédito do Programa Nacional de Fortalecimento da Agricultura Familiar - Pronaf, voltadas para a agroecologia e agrofloresta. Estas linhas de crédito são focadas no uso sustentável dos agroecossistemas e dos recursos florestais. Ao longo dos anos de existência do Programa, estas linhas de crédito vêm apresentando baixo desempenho, podendo ter como causa os obstáculos colocados pelos agentes financeiros para a aprovação de projetos, sob o argumento que existe uma carência de modelos de produção de sistemas agroflorestais e de sistemas agroecológicos que apresentem coeficientes técnicos e financeiros reconhecidos. Por outro lado, os projetos contratados ao abrigo do Pronaf-Agroecologia e Pronaf-Agrofloresta se mostram um valioso instrumento para a conservação da biodiversidade brasileira pelo fato de incorporarem princípios ecológicos baseados na conservação das espécies e na restauração das funções ecossistêmicas dos recursos naturais.
\end{abstract}

Palavras-chave: agricultura familiar; biodiversidade; multifuncionalidade; Pronaf.

\begin{abstract}
Initially, this work deals with the concept of multifunctionality of agriculture and discusses the international debate around this issue, which sets two groups of countries in opposite sides. Then, this work lists the roles played by the family farming in Brazil, defending the view point that Brazil does meet the agriculture environmental role, by allocating subsidized funds to family farmers in two Lines of credit from the National Program for the Strengthening of Family Farming - Pronaf, dedicated, mainly, to agroecology and agroforestry. These lines of credit focus on the sustainable use of agroecossystems and forestry resources. Through the years of the existing Program its credit policies have shown low perfor-
\end{abstract}

\footnotetext{
"Engenheiro Florestal. Analista ambiental pelo Instituto Chico Mendes de Conservação da Biodiversidade e Doutorando pelo Centro de Desenvolvimento Sustentável da Universidade de Brasília. Email: roger.magal@yahoo.com.br.
} 
mance maybe in spite of the Draconian policies of evaluation/analysis made by the financial analyzers to approve the projects based on the arguments of lack for models of agroforestry systems production and also lack for ecological crops systems that show acknowledge technical and financial rates. On the other hand, the projects supported by the Agroforestry and Agroecology Pronaf have shown to be a valuable tool for biodiversity conservation in Brazil, once they incorporate ecological principles based on the species conservation and restoration of ecosystem functions of natural resources.

Key-words: family farming; biodiversity; multifuncionality; Pronaf.

\section{Introdução}

O termo "multifuncionalidade da agricultura" pode ser definido como o "conjunto das contribuições da agricultura para um desenvolvimento econômico e social considerado na sua globalidade" (LAURENT, 1999). De acordo com esse conceito, essa multifuncionalidade consistiria em um conjunto de funções ou serviços com os quais a agricultura contribui para a sociedade, além daquela função fundamental de fornecimento de fibras e alimentos.

A multifuncionalidade como uma característica da atividade agrícola não é nova no mundo. Desde que o homem do neolítico alterou o seu modo de vida, passando de coletor-caçador - que o compelia a se deslocar continuamente em busca de fontes de alimentação - para agricultor, estabelecendo-se em um mesmo local onde as condições naturais eram propícias para plantar e colher, pode-se dizer que a agricultura vem cumprindo funções ambientais, econômicas e sociais, além daquela de produzir alimentos, fibras e combustíveis.

Porém, só recentemente o assunto ganhou destaque, desdobrando-se a partir dos embates ocorridos no âmbito da Organização Mundial do Comércio (OMC) sobre o comércio de bens agrícolas. Esses embates colocaram em posição antagônica dois grupos de países. De um lado, a Comunidade Europeia, que defende um determinado modelo de agricultura, com o objetivo de harmonizar as legislações agrícolas e de desenvolvimento rural dos países membros. De outro lado, os países menos desenvolvidos, que criticam duramente esse modelo e que enxergam, na promoção da multifuncionalidade nos países desenvolvidos, a manutenção de instrumentos protecionistas que restringem o acesso aos seus mercados e de subsídios que favorecem as suas exportações dirigidas para os mercados dos países do Terceiro Mundo (MALUF, 2000).

Esses países, notadamente aqueles que formam o Grupo de Cairns ${ }^{1}$, preocupados com o aumento da proteção que os países desenvolvidos concedem aos seus produtos rurais, propuseram: a) a eliminação de todas as formas de subsídios à exportação; b) o aumento substancial da abertura de mercado, por meio de profundo corte nas tarifas, nos picos tarifários, remoção de escalada tarifária e eliminação de medidas não tarifárias de cunho protecionista; c) uma maior redução no apoio distorcido à produção doméstica de mercado, com vistas a sua eliminação (SILVA, 2002).

Polêmicas sobre protecionismo à parte, deve-se levar em consideração o esforço dos países na proteção da sua agricultura, utilizando-se de diferentes iniciativas. Nesse sentido, alguns países da Comunidade Europeia vêm adotando políticas públicas voltadas para a proteção e o desenvolvimento das múltiplas funções da agricultura. Pode ser apontada como um exemplo a valorização dos produtos tradicionais provenientes do meio rural. Essa valorização é uma forma de agregar valor aos resultados do trabalho rural e de incrementar os ganhos dos agricultores com a sua produção. Iniciativas dessa natureza indicam um cuidado específico do Estado com a produção proveniente da agricultura.

Em Portugal, os esforços no sentido de agregar valor aos produtos tradicionais resultaram na criação de 80 denominações protegidas. Estão protegidos 10 tipos de produtos, como as carnes de ovinos, suínos, caprinos e bovinos; os queijos; os azeites; o mel; os produtos de salsicharia e os frutos. Esta proteção se estende a todo território português, ocorrendo com maior incidência no interior do país (ALMEIDA; MORAIS, 2001).

\footnotetext{
${ }^{1}$ Formado em 1986, em Cairns, Austrália, é composto atualmente por 19 países, sendo: África do Sul, Argentina, Austrália, Bolívia, Brasil, Canadá, Chile, Colômbia, Costa Rica, Filipinas, Indonésia, Guatemala, Malásia, Nova Zelândia, Paquistão, Peru, Paraguai, Tailândia e Uruguai.
} 
No entanto, esses autores destacam que, apesar do balanço global ser positivo, o processo de valorização de alguns produtos não alcançou os efeitos desejados. Entendem que os fatores de insucesso podem ser encontrados na defasagem entre os princípios normativos dos processos de valorização e as condições reais necessárias à implementação, manutenção e aperfeiçoamento dos mesmos. Esses fatores estariam vinculados à fraca capacidade organizativa, à dificuldade na definição de estratégias comerciais diferenciadas e menos dependentes de circuitos fora do controle dos produtores e, finalmente, a problemas de formação e informação nas cadeias produtivas.

No Brasil, apesar das tentativas de agregação de valor aos produtos tradicionais do meio rural, poucos resultados positivos foram obtidos até hoje. Pode ser citado o queijo de minas, que teve recentemente o seu modo de produção registrado no Inventário Nacional de Referências Culturais, sendo declarado patrimônio cultural imaterial pelo Instituto do Patrimônio Histórico e Artístico Nacional (IPHAN). Esse registro destaca a forma tradicional de se fazer queijo em quatro regiões do Estado de Minas Gerais: Serro, no nordeste; Serra da Canastra, na região central; Salitre/Alto Parnaíba, ou Serra do Oeste; e Araxá, no Triângulo Mineiro (LEMLE, 2008). No entanto, o produto ainda não obteve uma "denominação de origem", que certificaria que podem ser assim chamados apenas os produtos ou serviços cujas qualidades ou características se devam exclusivamente ao meio geográfico, incluindo fatores naturais e humanos genuinamente originados em determinada região. Além do mais, a estratégia adotada pelo IPHAN não garante ao produto o potencial de mercado que aqueles produtos com denominação de origem adquirem ao receberem tal proteção.

Embora muitas medidas para valorizar as funções da agricultura não alcancem os resultados desejados, é de se esperar que o Estado procure formas de proteger a agricultura, particularmente a familiar, em razão dos benefícios sociais e culturais que a permanência do homem no campo comprovadamente traz.

Este artigo demonstra que no mundo atual, em que um número significativo de países emprega políticas para valorizar as demais funções da agricultura que não somente aquela de produção de gêneros alimentícios e fibras, o Brasil atende a função ambiental da agricultura alocando recursos públicos aos agricultores familiares em linhas de crédito do Programa Nacional de Proteção da Agricultura Familiar - Pronaf - voltadas para a agrofloresta e para a agroecologia, as quais incorporam conceitos baseados no uso sustentável dos recursos naturais. Por sua vez, os projetos contratados no âmbito destas linhas de crédito se constituem em valioso instrumento para a conservação da biodiversidade brasileira, uma vez que incorporam princípios ecológicos baseados na conservação das espécies de interesse agrícola e florestal e na restauração das funções ecossistêmicas dos recursos naturais.

No presente texto, embora sejam mencionadas outras funções da agricultura, concentra-se o foco da análise na sua função ambiental. Outrossim, parte-se da premissa de que os sistemas agroecológicos e agroflorestais incorporam parcela significativa da biodiversidade agrícola e nativa quando comparados às pastagens plantadas e monocultura de grãos predominantes na paisagem agrícola nacional.

\section{Surgimento da noção e do conceito de multifuncionalidade}

A primeira menção sobre a noção de multifuncionalidade na agricultura ocorreu no programa de atividades da Agenda 21, aprovada pela Conferência das Nações Unidas sobre Meio Ambiente e Desenvolvimento (CNUMAD), ocorrida na cidade do Rio de Janeiro, em 1992 (SOARES, 2000/2001; SABORIN, 2003). O termo aparece mais especificamente no item 14.4(a) ${ }^{2}$, que sugere a "revisão, planejamento e programação integrada da política agrícola, à luz do aspecto multifuncional da agricultura, em especial no que diz respeito à segurança alimentar e ao desenvolvimento sustentável" (AGENDA 21, 2008).

Abramovay (2002) sustenta que a reforma da Política Agrícola Comum (PAC) de 1992, promovida no âmbito da Comunidade Europeia (CE), pode ser entendida como o evento que deu início às discussões sobre a multifuncionalidade da agricultura no âmbito do continente europeu. No entanto, esta reforma apresentava uma contradição fundamental, pois ao substituir a sustentação de preços pela ajuda direta aos agricultores da Europa, não tinha em vista o pagamento de funções múltiplas, socialmente valorizadas e não remuneradas pelo mercado, mas, sim, garantir o lugar

\footnotetext{
${ }^{2}$ Capítulo 14 - Promoção do desenvolvimento rural e agrícola sustentável.
} 
dos maiores produtores europeus no mercado mundial. $\mathrm{O}$ autor destaca que, por outro lado, essa reforma abriu caminho para que as discussões sobre a ajuda pública à agricultura fossem colocadas em evidência, tanto em nível internacional como no âmbito das sociedades europeias. Esse questionamento conduziu a transformações no PAC, que levaram vários países a adotarem legislação sobre a matéria.

Na França, a noção de multifuncionalidade está inserida nas leis de orientação relativas à agricultura, a exemplo da Lei de Ordenamento Agrícola ${ }^{3}$ e Lei de Orientação do Desenvolvimento Durável do Território ${ }^{4}$. No âmbito dessa legislação, são estabelecidos $\operatorname{contratos}^{5}$ de desenvolvimento entre o Estado e as regiões, os quais podem formar um programa de ações estabelecendo as atividades a serem desenvolvidas e os recursos financeiros para o seu custeio, de modo que cada parte tenha as suas obrigações delimitadas. As ideias-chave contidas nesse ajuste são: a) "processo negociado" entre os poderes públicos e os agricultores, nos marcos de um "contrato social" entre os rurais e o conjunto da sociedade, como formas contratuais específicas; b) redução das "assimetrias do mercado" e das "externalidades negativas" sobre o ambiente; e c) vínculo com um "território" (MALUF, 2000).

Porém, o tema ganhou maior repercussão por ocasião das negociações sobre agricultura ocorridas no âmbito da Organização Mundial do Comércio - OMC. Embora as discussões sobre o caráter multifuncional da agricultura tenham se iniciado na Rodada Uruguay do GATT (19861994), foi durante a Rodada de Doha que ocorreram os maiores questionamentos acerca da política agrícola adotada pela União Europeia - UE. A UE defendia a ideia de que era necessário conceder subsídios às unidades de produção agropecuária dos seus respectivos países, em razão do caráter multifuncional da agricultura.

A questão tomou vulto em razão de o Acordo em Matéria de Agricultura, aprovado em 1994 no âmbito da Rodada Uruguay, prever a necessidade de se estabelecer um sistema de trocas agrícolas orientadas pelo mercado, reconhecendo, ao mesmo tempo, a importância de se levar em conta as "considerações não diretamente comerciais" (non-trade concerns), a exemplo de segurança alimentar e de proteção ambiental (ABRAMOVAY, 2002).
Ficou evidente a divergência entre os países membros da OMC sobre o comércio agrícola. Formaram-se dois blocos. De um lado estavam os países que compõem o Grupo de Cairns, exportadores de produtos agropecuários que reivindicavam a liberalização do comércio de bens agrícolas e a remoção de barreiras comerciais na Europa, Estados Unidos e Japão aos seus produtos agropecuários. De outro estavam os países da União Europeia, que lançaram mão da noção de multifuncionalidade da agricultura para justificar os subsídios que concediam à sua agricultura. Argumentavam que as funções múltiplas exercidas pela atividade na Europa exigiam que não lhe fosse aplicado um tratamento meramente comercial. Com essa manobra, os europeus buscavam a manutenção dos subsídios que concediam à sua agricultura com base no argumento da multifuncionalidade (SOARES, 2000/2001). Atualmente, a promoção da multifuncionalidade da agricultura, não somente na França, mas em toda a Europa, está associada a uma estratégia de alocação individual e contratual de recursos públicos aos agricultores para remunerar as funções sociais e ambientais de interesse publico associadas à produção (FAO, 1999; MALUF, 2000).

Em 2002, aproximadamente $90 \%$ das unidades agropecuárias existentes em território francês recebiam ajuda direta do Estado. Desse montante, $75 \%$ recebiam auxílio por estarem produzindo cereais e oleaginosas. Já no ano de 1995 anunciava-se que as unidades produtivas francesas dedicadas à exploração de grãos dependiam inteiramente deste mecanismo de transferência de renda pública para o seu funcionamento (ABRAMOVAY, 2002).

As discussões sobre o conceito de multifuncionalidade da agricultura receberam importante estímulo a partir da Declaração do Comitê Ministerial para a Agricultura da $\mathrm{OECD}^{6}$, reunido em $1998^{7}$. Nesse documento foi reconhecido que, além da sua função primária de fornecer fibras e alimentos, a atividade agrícola pode moldar a paisagem, prover benefícios ambientais (como conservação dos solos, gestão sustentável dos recursos naturais renováveis e preservação da biodiversidade) e contribuir para a viabilidade socioeconômica de várias áreas rurais.

Da mesma forma, o documento analítico oriundo da Conferência Internacional Técnica sobre o Caráter Multi-

\footnotetext{
${ }^{3}$ LOI n. 99-574 du 9 juillet 1999 d'orientation agricole.

${ }^{4}$ LOI n. 99-533 du 25 juin 1999 d'orientation pour l'aménagement et le développement durable du territoire.

${ }^{5}$ Contratos Territoriais de Exploração (CTE).

${ }^{6}$ Organization for Economic Cooperation and Development.

${ }^{7}$ OECD - Committee for Agriculture at Ministerial Level, March 1998 (10).
} 
funcional da Agricultura e da Terra, organizada pela $\mathrm{FAO}^{8}$, em 1999, trouxe o entendimento de que a multifuncionalidade agrícola deriva da ideia de agricultura e desenvolvimento rural sustentável. Esse documento se propõe a promover um desenvolvimento sustentável (nos setores agrícola, pesqueiro e florestal) que venha a conservar a terra, a água e os recursos genéticos vegetais e animais, não degrade o meio ambiente, seja tecnicamente apropriado, economicamente viável e socialmente aceitável. Desse modo, o caráter multifuncional da agricultura poderia ser definido como toda a gama de funções ambientais, econômicas e sociais associadas à agricultura, englobando os múltiplos produtos e serviços gerados por ela. Esse conceito parte do princípio de que os sistemas agrícolas são intrinsecamente multifuncionais e desde sempre têm cumprido outras funções além daquela principal de produzir alimentos, fibras e combustíveis.

O conceito adotado pela FAO está vinculado a um novo critério analítico e de interpretação para melhor entender a complexidade e a importância contínua dos novos sistemas agrícolas presentes em todo o mundo. Ele serve também para avaliar as suas relações com outros setores da economia e da sociedade. No entanto, atualmente a noção de multifuncionalidade agrícola vem sendo associada à ideia de subvenções embutidas em políticas públicas destinadas à agricultura, como vem acontecendo na Europa.

Apesar de esse conceito estar atualmente atrelado a interesses internacionais de cunho comercial, pode-se afirmar que a agricultura possui funções à luz das quais devem ser analisadas as políticas públicas internas direcionadas para o setor, especialmente aquelas destinadas à agricultura familiar e o seu papel no desenvolvimento social das nações.

\section{Das funções desempenhadas pela agricultura familiar no Brasil}

Com o advento da "Revolução Verde" nas décadas de 60/70 - modelo de agricultura largamente utilizado em todo o mundo e que tem como pilares o monocultivo a partir de sementes híbridas, a larga utilização de fertilizantes químicos e agrotóxicos e a mecanização -, ocorreu um aumento significativo de danos ao meio ambiente: supressão de vegetação nativa em grande escala, poluição de cursos d'água por agrotóxicos e resíduos oriundos de adubação química, desertificação pelo uso intensivo do solo, desaparecimento da biodiversidade, entre outros (CROUCH, 1995).

No Brasil, o bioma que mais sofreu o impacto do modelo preconizado pela Revolução Verde foi o cerrado, em razão de a pesquisa agropecuária nacional ter adaptado várias tecnologias agrícolas (desenvolvidas principalmente nos EUA) aos solos do Planalto Central. Isso fez com que ano após ano ocorresse um aumento da produção de carne bovina e de grãos em larga escala. Além dos avanços proporcionados pelo desenvolvimento tecnológico, as próprias características físicas do cerrado contribuíram para o sucesso do modelo, tais como o clima tropical de inverno seco, as chuvas definidas e regulares, as temperaturas médias em torno de $22-23^{\circ} \mathrm{C}$ e os terrenos planos propícios à mecanização (PINTO, 1994; RIBEIRO; WALTER, 1998; SCARIOT; FELFILI; SOUZA-SILVA, 2005).

Se, por um lado, este modelo conduziu a um aumento da eficiência agrícola e pecuária, o que resultou em uma maior oferta de alimentos e produtos para exportação, por outro contribuiu para a desagregação social e econômica das populações rurais cuja cultura de subsistência foi suprimida, vindo a tornar-se assalariadas tanto no campo como nas cidades (DUARTE, 2002). Nas décadas de 70/80/90, assistiu-se ao maior êxodo rural da história do país. Por força das transformações ocorridas na agricultura, milhares de famílias deixaram o campo e se estabeleceram na periferia das cidades, somando-se ao contingente de desempregados e vivendo em condições de intensa vulnerabilidade social.

No âmbito dessas transformações, alguns eventos marcaram o meio rural durante a década de 90 conduzindo para a afirmação da agricultura familiar no cenário político e social brasileiro. Primeiramente, a luta das organizações de trabalhadores rurais e movimentos sociais para que tivessem reconhecidas as suas reivindicações a respeito de crédito rural e política de preços agrícolas. Em segundo lugar, a criação do Pronaf, em 1996, com o propósito de prover crédito agrícola e apoio institucional ao pequeno produtor rural que se encontrava alijado das políticas públicas direcionadas para o campo e em dificuldade para manter a sua atividade (SCHNEIDER, 2003).

Além desses dois elementos podemos destacar um terceiro que diz respeito à reorientação dos debates acadêmicos sobre o rural lato sensu (SCHNEIDER, 2003) e que

\footnotetext{
${ }^{8}$ Documento analítico - Conferência internacional técnica sobre o caráter multifuncional da agricultura e da terra. Maastricht (Países Baixos), setembro de 1999.
} 
colocou em cena questões como a conceituação da agricultura familiar. Cabe ressaltar que as discussões em torno do conceito de agricultura familiar se deram principalmente em função da necessidade de delimitar o papel social e econômico dessa categoria no âmbito da modernização da produção agropecuária no país.

Nesse escopo, a agricultura familiar como categorial social é aquela em que a família, sendo proprietária dos meios de produção, assume o trabalho no estabelecimento produtivo, se constituindo, desta forma, em uma categoria genérica, uma vez que a combinação entre propriedade e trabalho assume, no tempo e espaço, uma significativa diversidade de formas sociais. Nesse entendimento, a agricultura camponesa e a agricultura de subsistência são categorias particulares dentro da agricultura familiar, embora, em determinadas situações, agricultores possam organizar sua produção com vistas à sobrevivência imediata, sem vincular suas estratégias produtivas ao projeto futuro de família (WANDERLEY, 1999).

Nos termos do Pronaf, assim definido pela Lei n. ${ }^{\circ}$ 11.326/2006, agricultura familiar é aquela atividade rural desempenhada pelo agricultor que preencha os seguintes requisitos: a) seja detentor, a qualquer título, de área não superior a 4 (quatro) módulos fiscais; b) que use mão de obra predominantemente da própria família nas atividades econômicas do seu estabelecimento ou empreendimento; c) com renda familiar originada predominantemente de atividades econômicas vinculadas ao próprio estabelecimento ou empreendimento; e d) que administre seu estabelecimento ou empreendimento com sua família.

Apesar de uma definição não excluir a outra, na primeira, a autora, sob o ponto de vista acadêmico, busca caracterizar socialmente uma categoria presente em todo o território nacional, enquanto na segunda a legislação fornece os contornos da categoria para fins de enquadramento em uma determinada política pública. Embora não exista ainda um consenso sobre os exatos limites do termo, essa forma de agricultura desempenha funções importantes que devem ser levadas em consideração na formulação das políticas públicas que afetam a produção agrícola nacional.

Podem ser identificadas como funções-chave da agricultura familiar: a contribuição à segurança alimentar, a função ambiental, a função econômica e a função social (SOARES, 2000/2001):

(a) Contribuição à segurança alimentar - Comparativamente à agricultura patronal, sem dúvida a agricultura familiar é a que mais contribui para a produção de alimentos para a sociedade brasileira, afirmando-se como atividade estratégica para a segurança alimentar no Brasil. De acordo com os dados do INCRA (2000), os agricultores familiares geram $24 \%$ do valor bruto da produção (VBP) total da pecuária de corte, $52 \%$ da pecuária de leite, $58 \%$ dos suínos e $40 \%$ das aves e ovos. No que diz respeito a algumas culturas temporárias e permanentes, a agricultura familiar produz $33 \%$ do algodão, $31 \%$ do arroz, $72 \%$ da cebola, $67 \%$ do feijão, $84 \%$ da mandioca, $49 \%$ do milho, $32 \%$ da soja e $46 \%$ do trigo, $58 \%$ da banana, $27 \%$ da laranja e $47 \%$ da uva, $25 \%$ do café e $10 \%$ do VBP da cana-de-açúcar.

(b) A função econômica - A agricultura e a pecuária têm se constituído em importantes atividades para o crescimento econômico dos países, sejam desenvolvidos ou menos desenvolvidos, contribuindo para o desenvolvimento econômico. O Brasil atualmente tem na atividade agropecuária um importante fator de crescimento econômico. A agricultura familiar é um importante setor da economia brasileira, cujas cadeias produtivas participaram com 9\% do PIB em 2005 contra $18,9 \%$ da agricultura patronal. Em 2005, a cadeia produtiva da agricultura e da pecuária familiar contribuíram, respectivamente, com $19 \%$ e $13 \%$ do PIB das cadeias produtivas nacionais, enquanto a cadeia produtiva agrícola $\mathrm{e}$ pecuária patronal responderam, respectivamente, com 50\% e $18 \%$ (DIEESE, 2008).

A agricultura familiar no Brasil conta com 4,1 milhões de estabelecimentos, ocupando 14 milhões de pessoas, que produzem $60 \%$ dos alimentos do país e $10 \%$ do PIB nacional em 2004 (INCRA, 2000).

(c) A função social - A agricultura familiar no Brasil cumpre uma importante função de inserção social. A manutenção das paisagens rurais voltadas para a produção familiar é importante fator gerador de emprego e trabalho, principalmente para os jovens, que têm nela uma oportunidade para se inserir social e economicamente, deixando de migrar para a periferia dos grandes centros em busca de oportunidades que nem sempre encontram. Além do mais, os costumes, as manifestações culturais e as tradições religiosas têm forte efeito agregador sobre as comunidades rurais, além de serem geradores das identidades comunitárias. Esta forma de agricultura é a principal geradora de postos de trabalho no meio rural. Apesar de dispor de apenas 30\% da área agrícola, é responsável por 76,9\% do Pessoal Ocupado (PO). Dos 17,3 milhões de PO na agricultura brasileira, 13.780.201 estão empregados na agricultura familiar. Entre os agricultores 
familiares, 76,9\% utilizam-se exclusivamente do trabalho familiar em seus estabelecimentos (INCRA, 2000).

(d) A função ambiental - Não resta dúvida que a agricultura familiar desempenha importantes funções que devem ser consideradas na busca do desenvolvimento rural sustentável. Essa função, no entanto, somente poderia ser desempenhada por aquelas formas de exploração agrícola que utilizassem os recursos naturais levando-se em consideração seus limites físicos. Para Carmo (1998), a agricultura familiar possui esta aptidão porque incorpora características de diversificação/integração de atividades vegetais e animais e pelo fato de trabalhar em menor escala. Segundo a autora, todo agricultor detém um conjunto de práticas técnicas, econômicas e sociais coerentes com o sistema de exploração que adota. Compatibiliza os objetivos familiares com o meio ambiente, interagindo elementos e subsistemas muito além da constatação elementar da sua estrutura produtiva e das recomendações técnicas. Buainain (2002) não acha esta aptidão assim tão evidente. Para ele, são somente aqueles segmentos da produção agropecuária familiar não tão integrados aos circuitos agroindustriais e comerciais e com menor nível de intensificação tecnológica no processo produtivo - e que atribuem diferentes valores a determinados bens e serviços proporcionados pela natureza - que possuem potencial para este tipo de agricultura. Esses valores estariam em desacordo com as formas de exploração dos recursos naturais que adotam tecnologias agrícolas intensivas no uso do solo. Entretanto, o autor chama a atenção para o fato de que não é por pertencer a um núcleo familiar que explora a terra que o agricultor carrega a aptidão para o desenvolvimento de uma agricultura ambientalmente sustentável. Existem muitas evidências de práticas sustentáveis e virtuosas no âmbito da agricultura convencional e do agronegócio que não deveriam ser desprezadas, assim como existem práticas de agricultores familiares que levam à degradação dos solos e das águas e eliminam a biodiversidade.

Em face do grande número de agricultores que já adotaram práticas sustentáveis nas suas propriedades, ou que estão na fase de transição na direção de um uso mais sustentável dos recursos naturais, a agricultura familiar tem um importante papel a desempenhar na conservação ambiental, uma vez que abre a possibilidade para a minimização dos impactos ambientais ocasionados pelo cultivo da terra. A proteção desses recursos contribui para a conservação da biodiversidade e manutenção das funções ecossistêmicas dos recursos naturais, fundamental para a sustentabilidade dos sistemas cultivados. Além do mais, a vocação da agricultura familiar como unidade de produção e consumo, valoriza a diversidade por meio de policultivos e criações distribuídas de forma equilibrada no tempo e no espaço (SOARES, 2000/2001). É um modo camponês de fazer agricultura (VAN DER PLOEG, 2006) que, para se viabilizar sustentavelmente, depende em grande parte dos serviços ambientais proporcionados pela biodiversidade, tais como a fixação de carbono em florestas, a polinização realizada por insetos e pássaros autóctones, o controle de pragas levado a efeito por insetos nativos, o aumento da fertilidade do solo pela ação de micro-organismos, entre outros.

\section{A conservação e uso da biodiversidade e o Pronaf}

$\mathrm{O}$ termo biodiversidade significa a diversidade de formas de vida e é proveniente da contração da palavra diversidade biológica (biological diversity) (WILSON; PETER, 1988). Engloba todos os níveis de variação natural, do nível molecular e genético até o nível das espécies (HOUSTON, 1994). No entanto, o espectro de abrangência do conceito é muito amplo e existem dúvidas em torno do seu sentido exato (GASTON, 1996).

Os sistemas agroecológicos enfatizam a conservação-regeneração da biodiversidade. Nesses agrossistemas, fortalecer a biodiversidade funcional é a chave da estratégia para trazer sustentabilidade à produção. A riqueza de espécies do componente biótico desses agroecossistemas é comparável a muitos ecossistemas naturais (ALTIERI, 1999). No manejo orgânico ocorre uma maior riqueza de espécies, gêneros e famílias de espécies espontâneas do que com manejo convencional (STUPINO et al., 2007).

Nesses sistemas agrícolas, além da produção de alimentos, fibras, combustíveis e renda, a biodiversidade fornece serviços ambientais. São exemplos desses serviços a reciclagem de nutrientes, controle do microclima local, regulação do processo hidrológico local, regulação da abundância de organismos indesejáveis e eliminação de agrotóxicos (ALTIERI, 1999).

Em muitos sistemas agroecológicos, a biodiversidade não é mantida somente nas áreas cultivadas. Muitos agricultores familiares que adotam esses sistemas conservam parcela de vegetação natural próxima das suas plantações. 
Esses agricultores podem ser vistos como protagonistas importantes da transição à economia sustentável, já que, ao mesmo tempo em que são produtores de alimentos e outros produtos agrícolas, desempenham a função de conservadores da biodiversidade (SACHS, 2001).

A biodiversidade é essencial para a sustentabilidade da agricultura familiar (ALMEIDA et al., 2002). Esta sustentabilidade pode ser encontrada na própria estratégia dos agricultores de minimizar os riscos plantando várias espécies e variedades agrícolas que estabilizam a produção ao longo do tempo, promovem a diversidade alimentícia e maximizam os retornos sob baixos níveis de tecnologia e recursos limitados (RICHARDS, 1985).

A agroecologia e a agrofloresta têm sido apresentadas como modelos viáveis para a agricultura familiar pelo fato de se constituírem na forma de exploração dos recursos naturais que mais se adequam à realidade da produção com base familiar. Um dos mais importantes princípios agroecológicos a ser observado para a manutenção da capacidade produtiva e suficiente do agrossistema é a conservação da biodiversidade (ALTIERI, 2002), uma vez que exige a atuação de comunidades de plantas e animais junto ao seu ambiente físico e químico para a produção de alimentos. Nesse aspecto, a diversidade de espécies é de grande importância.

A agrofloresta pode ser considerada como uma abordagem integrada para conservação da biodiversidade (HUANG et al., 2002). Os sistemas agroflorestais tradicionais nos trópicos normalmente possuem acima de 100 espécies de plantas anuais e perenes por hectare (ALTIERI, 1999). As árvores que fazem parte desses sistemas também proporcionam um habitat para os pássaros e animais. Uma plantação de café com sombra no México pode conter até 180 espécies de pássaros que ajudam no controle de pragas e na dispersão de sementes (THRUPP, 2003). Numa área de 15 ha de Reserva Legal localizada no Pontal do Paranapanema, Estado de São Paulo, recomposta por meio de um sistema agroflorestal, foram encontradas 62 espécies vegetais diferentes distribuídas em 29 famílias, num total de 956 indivíduos vivos amostrados (RODRIGUES; GALVÃO, 2006).

Atualmente, em diversas partes do mundo, governos têm apoiado estratégias voltadas para práticas agroecológicas envolvendo o manejo da biodiversidade agrícola e a implantação de sistemas agroflorestais que buscam garantir o autoconsumo por parte de populações rurais mais pobres e a produção de excedentes comercializáveis.

No Brasil, o Programa Nacional de Fortalecimento da Agricultura Familiar (Pronaf), criado pelo Governo Federal em $1996^{9}$, pode ser visto como uma dessas iniciativas. Tem como objetivo promover o desenvolvimento sustentável do segmento rural constituído por agricultores familiares e opera na forma de concessão de crédito subsidiado para investimento e custeio ${ }^{10}$.

Além das linhas de financiamento convencionais, o agricultor familiar dispõe de linhas especiais de apoio aos produtos da biodiversidade: o Pronaf-Agroecologia e o Pronaf-Floresta:

O Pronaf-Floresta - Esta linha de crédito é destinada àqueles(as) agricultores(as) familiares interessados na implantação dos seguintes projetos: a) sistemas agroflorestais (SAF); b) exploração extrativista ecologicamente sustentável e plano de manejo florestal; c) recomposição e manutenção de áreas de preservação permanente e reserva legal e recuperação de áreas degradadas, para o cumprimento de legislação ambiental; d) enriquecimento de áreas que já apresentam cobertura florestal diversificada, com o plantio de uma ou mais espécies florestais, nativas do bioma. No Pronaf Florestal consta a exigência de que os plantios sejam consorciados, não sendo possível submeter projetos de monocultivo (MDA, 2008).

O PRONAF-Agroecologia - Criada no âmbito do Pronaf, em 2005, esta linha de crédito se destina a agricultores familiares interessados em desenvolver sistemas de produção agroecológicos e/ou orgânicos ou que já utilizam sistemas agroecológicos ou orgânicos, incluindo-se os custos relativos à implantação e manutenção.

Foi implementada para atender aos agricultores que optaram por uma agricultura ecológica na sua propriedade e que não tinham acesso às linhas de crédito convencionais oferecidas pelo Programa nos primeiros anos de operação. Naquelas circunstâncias, os agentes financeiros credenciados não reconheciam os métodos de manejo agroecológico pelo fato de seguirem à risca as técnicas recomendadas pelas instituições públicas e privadas de ensino e de pesquisa agrícolas envolvidas na geração de informações voltadas para a agricultura comercial. De acordo com essas recomendações, os recursos de custeio somente seriam liberados

\footnotetext{
${ }^{9}$ Decreto n. 1.946, de 28 de junho de 1996.

${ }^{10}$ As taxas de juros variam de 1 a $4 \%$ ao ano.
} 
caso fossem destinados à aquisição de insumos tais como fertilizantes químicos, agrotóxicos e cultivares de alta produção comercial. Do mesmo modo, os financiamentos para investimento destinavam-se à obtenção de máquinas e equipamentos desenvolvidos para este tipo de agricultura. Assim, os recursos financeiros sacados pelos agricultores familiares para custeio ou investimento da sua safra tinham como destino final as empresas agroindustriais (VON DER WEID, 2006).

TABELA 1 - NÚMERO DE CONTRATOS E MONTANTE FINANCIADO PELO PRONAF - 1998-2008

\begin{tabular}{c|c|c}
\hline Ano & $\mathbf{N}^{\mathbf{0}}$ Contratos & Montante (R\$ 1,00) \\
\hline $1998 / 1999$ & 174.286 & $416.368 .553,83$ \\
$1999 / 2000$ & 926.422 & $2.149 .434 .466,14$ \\
$2000 / 2001$ & 893.112 & $2.168 .486 .228,50$ \\
$2001 / 2002$ & 932.927 & $2.189 .275 .083,64$ \\
$2002 / 2003$ & 904.214 & $2.376 .465 .864,08$ \\
$2003 / 2004$ & 1.390 .168 & $4.490 .478 .228,25$ \\
$2004 / 2005$ & 1.635 .051 & $6.131 .600 .933,40$ \\
$2005 / 2006$ & 1.913 .043 & $7.611 .929 .143,94$ \\
$2006 / 2007$ & 1.692 .498 & $8.432 .952 .800,22$ \\
$2007 / 2008$ & 1.649 .063 & $9.074 .785 .135,73$ \\
$2008 / 2009$ & 1.443 .218 & $10.791 .907 .306,56$ \\
\hline Total & $\mathbf{1 3 . 5 5 5 . 5 7 9}$ & $\mathbf{5 5 . 8 3 3 . 6 8 3 . 7 4 4 , 2 9}$ \\
\hline
\end{tabular}

FONTE: MDA, 2010.

Desde que teve início, o Pronaf vem apresentando um volume crescente no valor contratado (Tabela 1). A Tabela 2, abaixo, mostra que o Pronaf-Floresta teve um crescimento considerável no número de contratos entre as safras de 2002 e 2007. No ano do seu lançamento, em 2002, foram assinados 25 contratos. Nessa época, esta linha de crédito era liberada somente para algumas regiões-piloto no Brasil, sendo estendida posteriormente para todo o país. Porém, na safra 2007/2008, houve uma queda significativa no número de contratos pactuados, bem como no total financiado. Na safra 2007/2008, o valor dos empréstimos não alcançou metade do valor financiado na safra anterior (Tabela 3 ).

O Pronaf-Agroecologia teve uma dinâmica semelhante. Na safra 2007/2008, o valor financiado sofreu uma queda de aproximadamente $22 \%$ quando comparado à safra 2006/2007, vindo a se recuperar na safra 2008/2009, tendo, inclusive superado o valor financiado naquela safra em cerca de 4,8\% (Tabela 3).

De acordo com Gomes ${ }^{11}$, uma das principais causas do Pronaf-Floresta e Pronaf-Agroecologia estarem sendo pouco demandados, quando comparados a outras linhas de crédito do Programa, é que os agentes financeiros credenciados (Banco da Amazônia, Banco do Brasil e Banco do Nordeste do Brasil) não estão dispostos a assumir o risco de conceder financiamentos no âmbito dessas linhas de crédito em razão da falta de modelos de produção de SAF e de sistemas agroecológicos que apresentem coeficientes técnicos e financeiros reconhecidos. Outros motivos para a baixa procura por aquelas linhas de crédito são: a difícil comprovação da rentabilidade financeira dos SAF e atividades de exploração extrativista quando comparados com a obtida em plantios com espécies exóticas de rápido crescimento; a indefinição de mercados para a comerciali-

TABELA 2 - NÚMERO DE CONTRATOS DAS LINHAS DE CRÉDITO DO PRONAF - 2002-2008

\begin{tabular}{l|c|c|c|c|r|r|c}
\hline \multirow{2}{*}{$\begin{array}{l}\text { Linha de crédito } \\
\text { do Pronaf }\end{array}$} & \multicolumn{9}{c}{ Número de contratos } \\
\cline { 2 - 9 } & $\begin{array}{c}\text { Safra } \\
\mathbf{2 0 0 2 / 2 0 0 3}\end{array}$ & $\begin{array}{c}\text { Safra } \\
\mathbf{2 0 0 3 / 2 0 0 4}\end{array}$ & $\begin{array}{c}\text { Safra } \\
\mathbf{2 0 0 4 / 2 0 0 5}\end{array}$ & $\begin{array}{c}\text { Safra } \\
\mathbf{2 0 0 5 / 2 0 0 6}\end{array}$ & $\begin{array}{c}\text { Safra } \\
\mathbf{2 0 0 6 / 2 0 0 7}\end{array}$ & $\begin{array}{c}\text { Safra } \\
\mathbf{2 0 0 7 / 2 0 0 8}\end{array}$ & $\begin{array}{c}\text { Safra* } \\
\mathbf{2 0 0 8} / \mathbf{2 0 0 9}\end{array}$ \\
\hline Floresta & 25 & 612 & 1.758 & 3.339 & 5.356 & 2.248 & 1.307 \\
Agroecologia & - & - & - & 42 & 260 & 191 & 216 \\
Outras linhas & 904.189 & 1.389 .556 & 1.633 .293 & 1.909 .663 & 1.686 .936 & 1.646 .624 & 1.441 .695 \\
\hline Total & 904.214 & 1.390 .168 & 1.635 .051 & 1.913 .044 & 1.692 .552 & 1.649 .063 & 1.443 .218 \\
\hline
\end{tabular}

* Dados até 31/03/2009

FONTE: MDA, 2010.

${ }^{11}$ GOMES, A. Ministério do Desenvolvimento Agrário, Secretaria de Agricultura Familiar. Comunicação pessoal, 2007. 
TABELA 3 - VALOR DO FINANCIAMENTO DAS LINHAS DE CRÉDITO DO PRONAF - 2002-2008

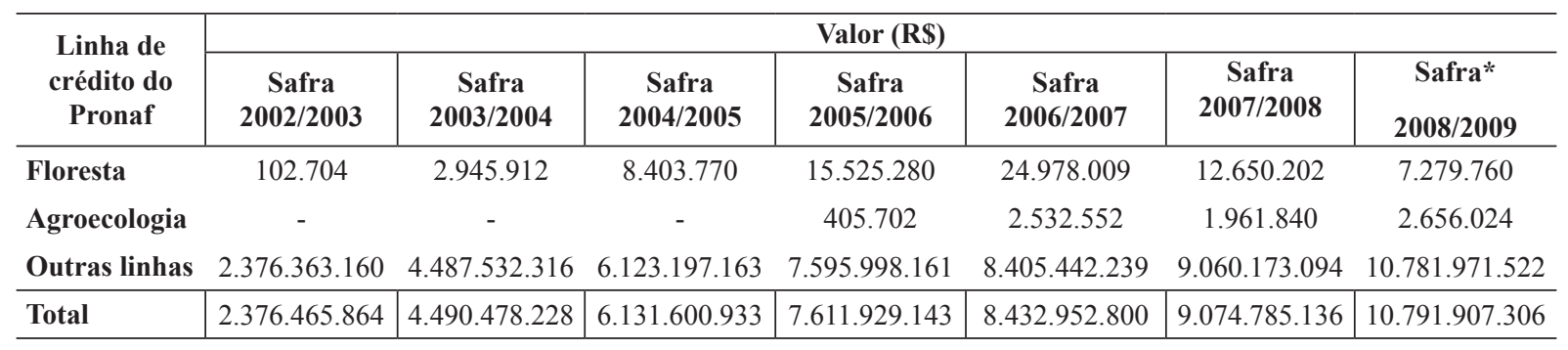

(*) Dados até 31/03/2009

FONTE: MDA, 2010.

zação da produção dos SAF e exploração extrativista; e a inexistência de cadeias estruturadas de insumos necessários para a agroecologia e para os SAF.

Outra razão apontada por Gomes $(2010)^{12}$ para a queda no número de projetos contratados e do montante financiado ao abrigo do Pronaf-Floresta, no ano de 2008, diz respeito às alterações das normas que regem esta linha crédito pela Resolução BACEN n. ${ }^{\circ} 3.559$, de 28 de março de 2008. Além de ser direcionada exclusivamente para o financiamento de sistemas agroflorestais, a referida Resolução também diminuiu as taxas de juros dos $2 \%$ a $5,5 \%$ anuais praticados anteriormente para $1 \%$ a $2 \%$ ao ano. Esse dispositivo legal foi reforçado pela Portaria n. ${ }^{\circ} 75$, de 8 de setembro de 2008, da Secretaria de Agricultura Familiar do Ministério do Desenvolvimento Agrário.

Estas novas regras vedaram os financiamentos voltados para implantação ou manutenção de projetos com menos de três espécies florestais ou destinados prioritariamente para uso industrial ou queima, entendendo-se por espécie florestal aquelas "domesticadas ou não, geradoras de diferentes produtos, madeireiros e não madeireiros" desde que utilizadas em consorciação com cultivos agrícolas na mesma área. Nesse sentido, os projetos destinados a plantios florestais homogêneos não poderão mais utilizar recursos daquela linha de crédito, devendo ser financiados com a linha geral de investimento do Pronaf, com risco bancário, ou pelo recém-criado Pronaf-Energia Renovável e Sustentabilidade Ambiental (Pronaf-Eco).

Apesar das razões apresentadas pelo Ministério do Desenvolvimento Agrário para a redução das contratações ao abrigo do Pronaf-Floresta e Pronaf-Agroecologia, o que podemos observar é que enquanto o valor financiado pelo Programa no período 2008/2009 cresceu aproximadamente $28 \%$ (Tabela 1), em relação ao período de 2006/2007, o valor contratado no âmbito do Pronaf-Floresta, no ano agrícola 2008/2009, é três vezes menor do que o valor contratado em 2006/2007, enquanto o valor financiado pelo Pronaf-Agroecologia no mesmo período - cerca de $0,24 \%$ do total do Programa - permanece estável.

Em sendo a ausência de modelos de produção de SAF e de sistemas agroecológicos a causa principal do baixo número de contratações naquelas linhas de crédito, fica patente que o Pronaf não conseguiu implementar alternativas ao padrão convencional de agricultura baseado no uso de fertilizantes químicos, agrotóxicos e máquinas. Essa evidência aponta para uma incoerência existente nos fins do Programa, de promoção do desenvolvimento sustentável do segmento rural constituído pelos agricultores familiares ${ }^{13}$.

\section{Considerações finais}

O raciocínio desenvolvido no presente texto conduz a duas conclusões distintas. A primeira nos permite inferir que um dos principais motivos para o baixo número de contratos no Pronaf-Floresta e Pronaf-Agroecologia seja resultado do deficiente conhecimento dos agentes financeiros a respeito dos coeficientes técnicos empregados nos sistemas agroflorestais e agroecológicos. Para suprir tal deficiência, os bancos estabelecem garantias e exigências contratuais que dificilmente o agricultor familiar tem como atender. Nesse sentido, é imperativo que os atores envolvidos no

\footnotetext{
${ }^{12}$ GOMES, A. Ministério do Desenvolvimento Agrário, Secretaria de Agricultura Familiar. Comunicação pessoal, 2010.

${ }^{13}$ Art. 1. ${ }^{\circ}$ do Decreto n. 1.946, de 28 de junho de 1996.
} 
Pronaf - agricultores, Ministério do Desenvolvimento Agrário, agentes financeiros, assistência técnica e extensão rural, pesquisa, comissões estaduais - busquem soluções que tornem estas linhas de crédito mais acessíveis aos agricultores interessados.

Na base destas soluções deve estar o compromisso de a pesquisa agropecuária nacional e a assistência técnica e extensão rural, em conjunto, agilizarem a construção de coeficientes técnicos que tragam a segurança requerida pelos agentes financeiros. Estes, por seu lado, devem flexibilizar suas exigências para que os agricultores invistam nas suas atividades e ampliem a área plantada. $\mathrm{O}$ aumento no número de contratos pactuados certamente contribuirá para uma elevação na área cultivada, promovendo benefícios para a biodiversidade funcional.

Outras iniciativas deverão ser tomadas para incrementar o número de contratos no âmbito das duas linhas de crédito mencionadas: reavaliação das normas que regulam as operações de crédito de custeio e de investimento para sistemas agroflorestais e agroecologia no sentido de torná-las menos onerosas aos tomadores; aumento no número de profissionais da assistência técnica com preparação adequada para atender aos agricultores que desejam implantar agricultura agroecológica e sistemas agroflorestais, levando ao campo a discussão democrática sobre os modelos de produção mais adequados às realidades socioeconômicas das famílias assistidas; ampliação do número de pesquisas na área florestal e agroecológica, valorizando as metodologias participativas e a produção de conhecimentos apropriados para o desenvolvimento rural sustentável; promover estudos de mercado local, regional e nacional para as cadeias produtivas de produtos agroflorestais e agroecológicos, com ênfase em mercados diferenciados, no sentido de inserção econômica do agricultor familiar neste importante nicho.

A segunda conclusão conduz ao raciocínio de que, apesar de ter criado o Pronaf-Floresta e Pronaf-Agro- ecologia para atender compromissos assumidos junto aos movimentos socais do campo interessados na agrofloresta e agroecologia, o governo federal não vem fornecendo as condições necessárias para que os agricultores acessem estas linhas de crédito, seja pelo aumento das exigências para a concessão de crédito e aprovação de contratos por parte dos agentes financeiros, seja pelo pouco empenho dos órgãos responsáveis pela implantação do Programa em desenvolver mecanismos que facilitem o acesso do agricultor familiar a estas linhas de crédito. Essa postura revela a importância secundária que o governo vem dispensando à sustentabilidade ambiental na agricultura.

Não resta dúvida que o Pronaf vem se evidenciando como uma das mais importantes políticas públicas para o meio rural brasileiro no período recente. Dessa forma, tornou-se um valioso instrumento de apoio à agricultura familiar no país. Uma prova disso são os números apresentados no presente trabalho, que demonstram um crescimento significativo tanto no montante de recursos disponibilizados e aplicados quanto no número de beneficiários atendidos.

Apesar da avaliação positiva do Programa como um todo, as duas linhas de crédito em análise apresentam resultados pouco expressivos e são merecedoras de um debate mais aprofundado a respeito do modelo de uso do solo que querem trazer. No entanto, devemos levar em consideração que, mesmo com o baixo desempenho apresentado, valorizam a função ambiental da agricultura, pois incorporam princípios da agroecologia e da agrofloresta que se baseiam no uso sustentável dos recursos naturais. Os agrossistemas implementados por força dessas duas linhas de crédito, pelo fato de exigirem a manipulação de um significativo número de espécies vegetais e, dependendo do caso, até mesmo espécies animais (quando o sistema prever a associação com a pecuária), podem se constituir em um valioso instrumento de restauração das funções ecossistêmicas dos recursos ambientais e a conservação da diversidade biológica no país. 


\section{Referências}

ABRAMOVAY, R. Subsídios e multifuncionalidade na política agrícola europeia. Economia Rural, v. 40, n. 2, p. 235-264, abr./jun. 2002.

AGENDA 21. Disponível em: <http://www.crescentefertil.org. br/agenda21/index2.htm $>$. Acesso em: 13/09/2008.

ALMEIDA, C.; MORAIS, L. A conflitualidade nos processos de valorização dos produtos tradicionais. In: COLOQUIO HISPANO-PORTUGUÉS DE ESTUDIOS RURALES, IV. Santiago de Compostela, junho de 2001. Disponível em: $<$ http:// www.usc.es/ idega/ celestinoa.doc $>$. Acesso em: junho de 2008.

ALMEIDA, P.; PETERSEN, P.; TARDIN, J. M. Conservando a biodiversidade em ecossistemas cultivados: ação comunitária na manutenção de variedades locais no Agreste da Paraíba e no Centro-Sul do Paraná. In: BENSUSAN, N. (Org.). Seria melhor mandar ladrilhar?: biodiversidade como, para quê, por quê. Brasília: Instituto Socioambiental e Editora UnB, p. 147-157, 2002.

ALTIERI. M. A. Agroecología: princípios y estrategias para diseñar sistemas agrários sustentables. In: SARANDÓN, S. J. Agroecologia: el camino hacia una agricultura sustentable. La Plata: Ediciones Científicas Americanas, 2002.

ALTIERI, M. A. The ecological role of biodiversity in agroecosystems. Agriculture, Ecosystems and Environment, v. 74, issue 1-3, p. 19-31, 1999.

BUAINAIN A. M. Agricultura familiar, agroecologia e desenvolvimento sustentável: questões para debate. Série Desenvolvimento Rural Sustentável, v. 5. Instituto Interamericano de Cooperación para la Agricultura (IICA) - Brasil, Brasília, 2006.

CARMO, M. S. do. A produção familiar como lócus ideal da agricultura sustentável. In: FERREIRA, A. D. D.; BRANDENBURG, A. Para pensar outra agricultura. Curitiba: UFPR, 1998.

CROUCH, M. L. Biotechnology is not compatible with sustainable agriculture. Journal of Agricultural and Environmental Ethics, v. 8, n. 2, p. 98-111, sep. 1995.

DIEESE - Departamento Intersindical de Estatísticas e Estudos Socioeconômicos. Núcleo de Estudos Agrários e Desenvolvimento Rural. Estatísticas do meio rural 2008. Brasília: MDA e DIEESE, 2008. Disponível em: <http://www.mda.gov.br/ arquivos/estatisticas-rurais-2008.pdf $>$. Acesso em: setembro de 2008 .
DUARTE, L. M. G. Desenvolvimento sustentável: um olhar sobre os cerrados brasileiros. In: DUARTE, L. M. G.; THEODORO, S. H. (Orgs.). Dilemas do cerrado: entre o ecologicamente (in)correto e o socialmente (in)justo. Rio de Janeiro: Garamond, 2002.

FAO. Documento expositivo: Analisis del caracter multifuncional de la agricultura y la tierra. FAO/Netherlands Conference on the Multifunctional Character of Agriculture an Land. 12-17 september 1999. Maastricht, The Netherlands.

GASTON, K. J. What is biodiversity? In: (Ed.).

Biodiversity: a biology of numbers and difference. Oxford: Blakwell Science, p. 1-9, 1996.

HUANG, W.; LUUKKANEN, O.; JOHANSON, S.; KAARAKKAI, V.; RÄISÄNEN, S.; VIHEMÄKI H. Agroforestry for biodiversity conservation of nature reserves: functional group identification and analysis. Agroforestry Systems, n. 55 , p. 65-72, 2002.

HUSTON, M. A. Biological diversity: the coexistence of species on changing landscapes. Cambridge: Cambridge University Press, 1994.

INCRA. Projeto de Cooperação Técnica INCRA/FAO. Novo retrato da agricultura familiar: o Brasil redescoberto. Brasília, 2000.

LAURENT C. Activité agricole, multifonctionnalité et pluriactivité. Revue Pour, n. 164, p. 41-46, 1999.

LEMLE, M. Jeitinho mineiro de fazer queijo é patrimônio cultural imaterial. Revista de História da Biblioteca Nacional. Disponível em: <http:/www.revistadehistoria.com.br/ $\mathrm{v} 2 /$ home $/$ ?go $=$ secao\&secao=18> . Acesso em: maio de 2008 .

MALUF, R. S. O enfoque da multifuncionalidade da agricultura: aspectos analíticos e questões de pesquisa. In: LIMA, D. M. de A.; WILKINSON, J. (Orgs.). Inovação nas tradições da agricultura familiar. Brasília: CNPq/Paralelo 15, 2000.

MDA - Ministério do Desenvolvimento Agrário. Homepage Institucional. Disponível em: <http://www.mda.gov.br $>$. Acesso em: jun. 2008.

PINTO, M. N. (Org.). Cerrado: caracterização, ocupação e perspectivas. 2. ed. Brasília: Editora Universidade de Brasília, 1990.

RIBEIRO, J. F.; WALTER, B. M. T. Fitofisionomias do bioma cerrado. In: SANO, S. M.; ALMEIDA, S. P. de (Eds.). Cerrado: ambiente e flora. Brasília: EMBRAPA-CPAC, 1998. 
RICHARDS, P. Indigenous agricultural revolution: ecology and food-crop farming in West Africa. London: Hutchinson, 1985.

RODRIGUES, E. R.; GALVÃO, F. Florística e fitossociologia de uma área de reserva legal recuperada por meio de Sistema Agroflorestal na região do Pontal do Paranapanema, São Paulo. Floresta, v. 36, n. 2, p. 295-303, maio/ago. 2006.

SABOURIN, E. Multifuncionalidade da agricultura e manejo de recursos naturais: reflexão sobre alternativas a partir do caso do semiárido brasileiro. In: Textos do Seminário Franco-Brasileiro de Pesquisa sobre Multifuncionalidade da Agricultura [CD ROM], 24-27 novembro, Florianópolis, 2003.

SACHS, I. Brasil rural: da redescoberta à invenção. Estudos Avançados, v. 15, n. 43, p.75-82, set./dez. 2001.

SCARIOT, A.; FELFILI, J. M.; SOUZA-SILVA, J. C. (Eds). Cerrado: ecologia, biodiversidade e conservação. Brasília: Ministério do Meio Ambiente, 2005.

SILVA, V. da. O Grupo de Cairns e a defesa da liberalização do comércio agrícola mundial. 2002. Disponível em $<$ http://www. iea.sp.gov.br/OUT/verTexto.php?codTexto=108>. Acesso em: setembro de 2008.

SOARES, A. C. A multifuncionalidade da agricultura familiar. Proposta, n. 87, p. 40-49, dez./fev. 2000/2001.

SCHNEIDER, S. Teoria social, agricultura familiar e pluriatividade. Revista Brasileira de Ciências Sociais, v. 18, n. 51, p. 99-121, fev. 2003.
STUPINO, S. A.; FERREIRA, A. C.; FRANGI, J.; SARANDÓN, S. J. Agrobiodiversidad vegetal em sistemas horticolas organicos e convencionales. Revista Brasileira de Agroecologia, v. 2, n. 1, p. 339-342, fev. 2007.

THRUPP, L. A. O papel central da biodiversidade agrícola: tendências e desafios. In: Interação de gênero, da agrobiodiversidade e dos conhecimentos locais ao serviço da segurança alimentar. Manual de formação. FAO. 2005. Disponível em: $<$ http://www.fao.org/docrep/009/y5956p/Y5956P00.htm>. Acesso em: agosto de 2008.

VON DER PLOEG, J. D. O modo de produção camponês revisitado. In: SCHNEIDER, S. (Org.). A diversidade da agricultura familiar. Porto Alegre: Editora da UFRGS, 2006.

VON DER WEID, J. M. A transição agroecológica das políticas de crédito voltadas para a agricultura familiar. Revista Agriculturas, v. 3, n. 1, abr. 2006. Disponível em: $<$ http://www. agroecologia.org.br/modules/articles/artigo4.pdf $>$. Acesso em: junho de 2008 .

WANDERLEY, M. de N. B. Raízes Históricas do Campesinato Brasileiro. In: TEDESCO, J. C. (Org.). Agricultura familiarrealidades e perspectivas. 2. ed. Passo Fundo: EDIUPF, 1999.

WILSON, E. O.; PETER, F. M. Biodiversity. Washington: National Academies Press, 1988.

Recebido em janeiro de 2009.

Aceito em fevereiro de 2010.

Publicado em dezembro de 2010. 